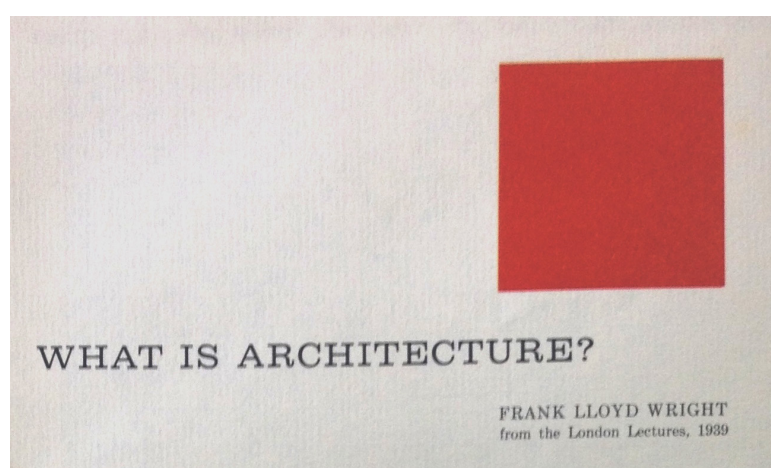

\section{O que é Arquitetura? (para Frank Lloyd Wright)}

What is Architecture? (to Frank Lloyd Wright)

\author{
Fernando Guillermo Vázquez Ramos*
}

*Professor no Curso e no Programa de Pós-graduação em Arquitetura e Urbanismo da Universidade São Judas Tadeu. Doutor (Universidad Politécnica de Madrid, 1992); Master em Estética y Teoria de las Artes (Instituto de Estética y Teoria de las Artes, 1990); Técnico em Urbanismo (Instituto Nacional de Administración Pública, 1988); Arquiteto (Universidad Nacional de Buenos Aires, 1979).

\section{Resumo}

Este dá início a uma série de artigos sobre o que é arquitetura. Esta primeira abordagem é um texto publicado em 1958 pela prestigiosa revista estadunidense The Architectural Forum, onde Frank Lloyd Wright (1887-1959) define justamente o que entendia ser a Arquitetura. A revista informava que se tratava de um excerto das conferências ministradas pelo arquiteto em Londres em 1939. Contudo, após minucioso estudo do texto, percebemos que essa informação sobre a fonte do material era imprecisa, o que nos levou a uma pesquisa mais detalhada dos originais que compõem o excerto publicado. $O$ artigo traz também a tradução ao português do referido material.

Palavras-chave: Essência da Arquitetura. Textos de Arquitetura. História da Arquitetura Moderna.

\section{Abstract}

This text gives rise to a series of articles on what is Architecture. This first approach is an article published in 1958 by the prestigious US magazine The Architectural Forum, in which Frank Lloyd Wright (1887-1959) precisely defined what he understood to be Architecture. The magazine reported that the text was an extract from the lectures given by Wright in London in 1939. However, after careful study of the text, we realized that the information on the source of the material was inaccurate, which led us to a more detailed research of the original texts that comprise the published extract. This article also brings the translation into Portuguese of the material.

Keywords: Essence of Architecture. Texts of Architecture. History of Modern Architecture. 


\section{Introdução}

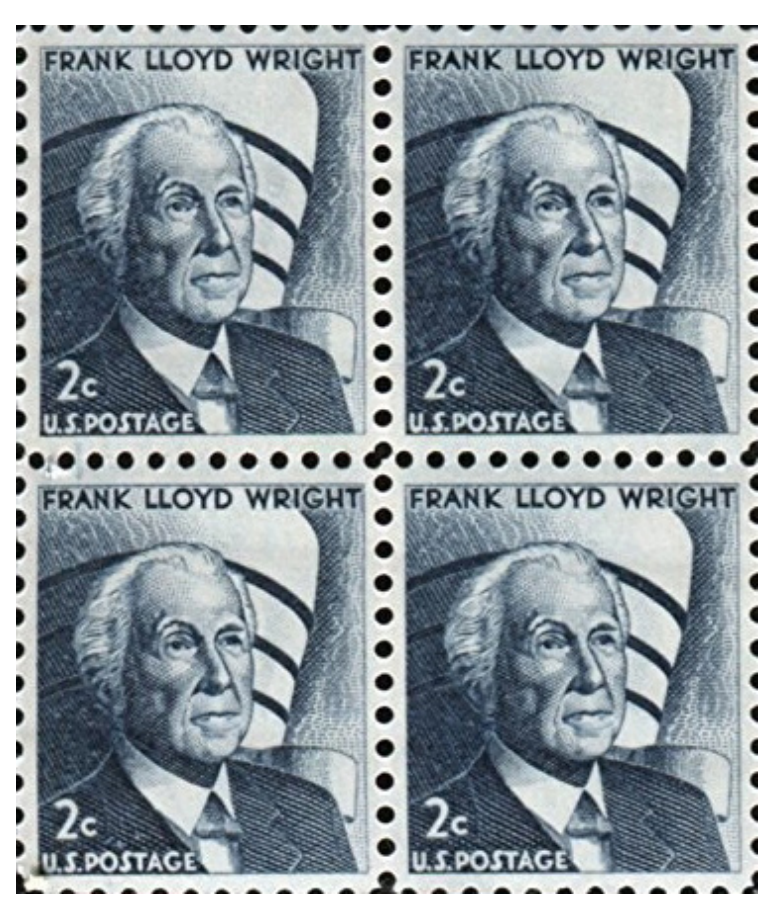

Figura 1. Selo comemorativo com a imagem de Frank Lloyd Wright em primeiro plano e do Museu Guggenheim de Nova York ao fundo. O selo, de 2 centavos, foi lançado em 1966, na série "Prominent American" (MYSTIC STAMP COMPANY, [s.d.]).

usjt • arq.urb • número 24 | janeiro - abril de 2019

\section{E} bram os 60 anos do falecimento do arquiteto estadunidense (talvez se pudesse dizer "usoniano") ${ }^{1}$ Frank Lloyd Wright (Figura 1), nascido em Wisconsin em 8 de junho de $1867^{2}$ e falecido aos 92 anos em Chicago, em 9 de abril de 1959. Exerceu sua profissão por mais de 70 anos, pois começou a trabalhar com arquitetura em Chicago em 1887, aos 20 anos, como desenhista no escritório de Joseph Lyman Silsbee ${ }^{3}$. Em 1888, foi contratado pelos arquitetos Dankmar Alder e Louis Sullivan ${ }^{4}$, que desenvolviam o projeto para o Auditorium Theater da Roosevelt University, obra emblemática da Escola de Chicago e hoje landmark do patrimônio arquitetônico dessa cidade. Um início promissor, no mais importante e renomado escritório de arquitetura da época em Chicago.

Este artigo também inicia uma série de textos que discutem definições de arquitetura ${ }^{5}$ dadas por im- portantes arquitetos no decorrer dos séculos, desde Leon Battista Alberti (com seu conhecido postulado "A arquitetura, em seu todo, compõe-se de delineamento e construção"6 [KRÜGER, 2011, p. 53])7 até nossos dias.

Como leitmotiv da série, adotamos o mesmo título do texto de Frank Lloyd Wright (1958, p.102) que traduzimos e comentamos: "O que é Arquitetura?" (What is Architecture?). Intrigante, pelas várias razões que veremos, o artigo foi publicado em 1958 na prestigiosa revista estadunidense The Architectural Forum.

É importante advertir que, embora a pergunta pareça muito singela, sua resposta não o é. O leitor notará também que escrevemos "Arquitetura", com inicial maiúscula, o que já indica uma flexão da escrita em favor do entendimento da "Arquitetura" não como um objeto, mas como um campo de um saber específico, enfatizando seu caráter substantivo, isto é, 
1. Wright não pensava que os cidadãos dos EUA devessem ser ditos "americanos" ou mesmo "estadunidenses", e escolheu dizê-los (inclusive a si mesmo) Usonians. Em suas palavras, "Eu não sei se alguns de vocês aqui [Londres, 1939] estão familiarizados com a palavra 'Usonia' para designar nosso país. 'Estadunidenses' não soa bem, e nós de fato não temos o direito de nos chamarmos 'Americanos', porque não temos o monopólio de esse título". ("I do not know whether some of you here are familiar with this word 'Usonia' for our country, 'United Statesers' doesn't sound well and we are not really entitled or call ourselves 'Americans', because we have not a monopoly of that title" [WRIGHT, 1953, p. 262, tradução nossa]). O termo Usonia fo cunhado pelo escritor inglês Samuel Butler, que o utilizou em seu romance Erewhon, de 1872 (COHEN, 2013, p. 228), e, no início do século XX, James Duff Law o popularizou para diferenciar estadunidenses de canadenses e mexicanos, também habitantes da América do Norte, pois, como Wright, não pensava que os habitantes de um país particular tivessem o direito de tomar para si o nome que designa todas as Américas. Kenneth Frampton $(2017$, p. 22) afirma que Wright começou a usar usonian em 1925, ainda que em outro texto diga que foi em 1928 (FRAMPTON, 2003, p. 226). Contudo, a primeira referência aparece em 1927 no texto "The Pictures We Make" (WRIGHT, 1941, p. 100, tradução nossa), onde Wright agradece a Butler por "fornecer-nos um bom nome" ("fitted us a good name"). Contudo, alguns autores pensam que esse assunto não passa de uma boutade entre "happenings ou provocações" do arquiteto e seu círculo (informações verbais de Paulo Yassuhide Fujioka).

2. Embora tenha afirmado durante grande parte de sua vida que nascera em 1869 (RAGON, 1971, p. 182 BLAKE, 1996, p. 288). Entre muitos outros, autores como Henry-Russell Hitchcock (1978, p. 19), Leonardo Benevolo (1976, p. 254) e Gillo Dorfles (1975, p. 65) dão essa como a data certa do nascimento do arquiteto. Se assim fosse, completaria agora 150 anos. dotado de substância. Assim, de um modo geral ou amplo e sem prejuízo de outras taxonomias possíveis, podemos congregar as respostas à pergunta "O que é Arquitetura?" em dois grandes grupos. $O$ primeiro seria o das descrições, que tratam de como é a Arquitetura. O segundo, o das essências, cujas respostas versam sobre o que ela é.

\section{Sobre descrições e essências}

O primeiro grupo destaca os aspectos constitutivos da arquitetura - seu modo de ser. Enuncia, menos ou mais amplamente, a forma pela qual essa disciplina se desenvolve no momento histórico em que se a define. Inclui as definições mais antigas, remontando a Marcus Vitruvius Pollio, que nunca explicou o que pensava que fosse a Arquitetura, mas descreveu, embora indireta e muito genericamente, como achava que se constituía: "A ciência do arquiteto é ornada de muitas disciplinas e de vários saberes, estando sua dinâmica presente em todas as obras oriundas das outras artes. Nasce da prática e da teoria"8 (VITRÚVIO, 2007, p. 61).

Ainda que mais timidamente, Alberti segue a mesma linha. Em sua definição, trata da constituição da Arquitetura, não de sua essência, o que condiz com sua condição de obra inaugural, porque no século XV a nascente disciplina precisava ser explicada, não questionada. Indiretamente, a esse grupo pertencem também os pensadores que situam a arquitetura dentro de uma forma específica do fazer; um bom exemplo é a definição de Marc-Antoine Laugier (1753, p. 1, tradução nossa):
A Arquitetura é, de todas as Artes úteis, aquela que exige os talentos mais distintos e os conhecimentos mais extensos. É necessário talvez tanto gênio, espírito e gosto para fazer um grande Arquiteto quanto para formar um Pintor ou um Poeta de primeira ordem. ${ }^{9}$

O grupo das essências é formado por definições que buscam o que há de especial e único na Arquitetura. São textos indagativos sobre o que a diferencia de outras artes ou ciências desde sempre, que evidencia sua natureza ou ser substantivo.

Sabedores de que no último século prosperou uma forma de pensar que questiona esse viés, não adentramos aqui o debate sobre a essência da Arquitetura (um algo a-histórico e eterno capaz de defini-la, que varia segundo o ponto de vista de cada autor), mas devemos admitir que durante séculos isso não foi assim, e a procura pelo ser mais íntimo da Arquitetura nos brindou com páginas maravilhosas. Não foram poucos os autores no passado que pensaram a Arquitetura trabalhando sob a influência dessa chave interpretativa. Ter em conta essa peculiaridade é importante quando lemos textos como o que apresentamos aqui.

Esse grupo compõe-se de definições mais modernas, em geral, posteriores ao século XVIII, pois, para definir a essência da arquitetura, é preciso separá-la de suas irmãs - pintura e escultura -, com as quais compartilhou durante séculos as mesmas circunstâncias. 
3. "Um arquiteto medíocre", segundo Michel Ragon (1971, p. 184, tradução nossa), e "um projetista de casas suburbanas", segundo William Curtis (2006, p. 114, tradução nossa). Paulo Y Fujioka discorda dessas afirmações, lembrando que Silsbee era "parente do Edward Morse, o grande pesquisador da arquitetura japonesa [...]. Muitos lhe atribuem a renovação do interesse de Wright pela arquitetura e pela arte japonesa, porquanto tivesse contato não só com Morse, mas com vários membros do grupo Boston Japanists". (Informação verbal.)

4. Wright chamava Louis Sullivan de Lieber Meister (amado mestre), uma expressão "tocante, ainda que linguisticamente incorreta" (BLAKE, 1966, p. 22).

5. Gostaríamos de incluir nesta série o artigo sobre a definição de Mies van der Rohe no aforismo de 1923 (VÁZQUEZ RAMOS, 2013).

6. "Tota res aedificatoria lineamentis et structura constituta est".

7. Tema que discutimos numa comunicação no VII Encontro de História da Arte (VÁZQUEZ RAMOS, 2011).

8. "Architecti est scientia pluribus disciplinis et variis eruditionibus ornata, cuius indicio probantur omnia quae ab ceteris artibus opera. ea nascitur ex fabrica et ratiocinatione" (MARCUS VITRUVIUS POLLIO, 2018).

9. "L'architecture est de tous les Arts utiles, celui que demande les talents les plus distingués, et les connaissances les plus étendues. II saut peut-être autant de génie, d'esprit et de goût pour faire un grand Architecte, que pour former un Peintre, et un Poëte du premier ordre" (adaptação ortográfica nossa).

10. As duas correntes no Brasil: Bachelard (1989, 2013)

11. O Cours d'Architecture de Blondel, publicado em 1771, tinha o sugestivo nome de Traité de la Décoration, Distribution \& Construction des Bâtiments.
As definições sobre o que é Arquitetura habitualmente são poéticas e ricas em figuras de linguagem, paráfrases ou alegorias; quase sempre são adjetivadas e assertivas e usam o verbo ser de forma direta e enfática. Podemos situar esse tipo de definição no que Gaston Bachelard (1961, p. 10, grifado no original, tradução nossa) chama de "imagem poética", que "é essencialmente variante", em oposição à realidade "constitutiva" do conceito. Para Bachelard, a imagem poética se abre à captação da "realidade específica" ("saisir la réalité spécifique") (BACHELARD, 1961, p. 10) da coisa, que poderia ser entendida como sua essência, em sentido lato.

Neste texto e para nosso objetivo, o que podemos entender por variante?

A tradução espanhola do texto do filósofo francês diz "variable" (BACHELARD, 2000, p. 10, grifado no original); em português, as traduções consultadas ${ }^{10}$ são bem menos precisas e dão uma palavra inexistente (ou, pelo menos, um neologismo): "variacional" (BACHELARD, 2013, p. 185; 1989, p. 3, grifo dos originais). Mas Bachelard (1961) usa um adjetivo feminino (variationnelle), e não um substantivo (variable). Embora variante e variável possam ser usados como adjetivos, o sentido de variável não parece coincidir com a intenção do autor, pois significa, entre outras coisas: volúvel, instável ou inconsistente. Entretanto, variante indica apenas a qualidade do que varia - daquilo que se relaciona a variações ("ayant trait aux variations") - que é a definição de variationnel (LE DICTIONNAIRE, [s.d.]).
Há dois aspectos do adjetivo variante que nos interessam. O primeira é sua relação com o que muda. Mudam o aspecto, a forma, a posição, o ponto de vista etc. Nesse sentido, tanto o grupo das descrições como o das essências são variantes, mas o primeiro muda de acordo com as circunstâncias históricas. Em muitos casos, pode ser fixo no que tange à descrição do objeto, mas variar seu significado. $\mathrm{O}$ caso típico é a tríade vitruviana: firmitas, utilitas e venustas. Durante séculos, essas palavras definiram as características principais da arquitetura, mas significam coisas bem diferentes para Alberti (necessitas, commoditas, voluptas) (KRÜGER, 2011, p. 23-24) e para Jacques-François Blondel (construction, distribution, décoration), ${ }^{11}$ por exemplo.

Também há mudança no grupo das essências, mas não em função da historicidade. Ao menos de um ponto de vista disciplinar e técnico, como acontece no grupo das descrições, em que mudam as próprias definições, que se abrem a interpretações. Elas mesmas são variantes.

A imagem poética é aberta e permite aberturas. Sendo consistente, não se constitui conceitualmente, não descreve a coisa, mas vibra em variações sobre ela, é "irisada" (irisée), como afirma Bachelard (1961, p. 10, tradução nossa). Como não se fixa numa descrição, a amplitude cromática desse tipo de imagem inclui a imaginação (tanto a do poeta-autor, como a do leitor) no jogo das definições, numa abordagem interpretativa que tende ao específico sem esgotá-lo. 
12. "Avec la poésie, l'imagination se place dans la marge où précisément la fonction de l'irréel vient séduire ou inquiéter - toujours réveiller - l'être endormi dans ses automatismes" (BACHELARD, 1961, p. 26).

13. "L'architecture est le jeu savant, correct et magnifique des volumes assemblés sous la lumière" (LE CORBUSIER, 1924, p. 16)

14. "Baukunst ist raumgefaßter Zeitwille. Lebendig. Wechselnd. Neu" (MIES VAN DER ROHE, 1923, p. 3).

15. "Baukunst ist immer der räumliche Ausdruck geistiger Entscheidung" (MIES VAN DER ROHE, 1928, p. 262).
Quando ligado a seu significado poético, o termo imagem tampouco deve ser usado em sentido amplo ou comum, mas na acepção de uma capacidade de produzir que têm as imagens. "Produtora" (productrice), diz Bachelard (1961, p. 25, tradução nossa) sobre a imagem poética, isto é, capaz de misturar as funções do real e do irreal. "Com a poesia, a imaginação coloca-se na margem em que precisamente a função do irreal vem arrebatar ou inquietar - sempre despertar - o ser dormido nos seus automatismos"12 (BACHELARD, 1989, p. 18).

Um exemplo paradigmático desse grupo (dentro da variante poética mais evidente) é a conhecida definição de Le Corbusier (1981, p. 13): “A arquitetura é o jogo sábio, correto e magnífico dos volumes reunidos sob a luz". ${ }^{13}$ As definições de Ludwig Mies van der Rohe constituem o viés metafísico (que compartilha as qualidades da imagem poética) do mesmo grupo: "A Arquitetura é a vontade da época que se agarra ao espaço. Viva. Cambiante. Nova"14 (MIES
VAN DER ROHE apud VÁZQUEZ RAMOS, 2013, p. 171), e " $A$ arquitetura é sempre a expressão espacial da determinação espiritual"15 (MIES VAN DER ROHE apud VÁZQUEZ RAMOS, 2016, p. 63).

Sem dúvida, "O que é Arquitetura?" de Wright é um exemplar do segundo grupo, com a particularidade de que logra reunir o lado poético com o metafísico. É um texto que pergunta o que é essencial (a natureza e o ser da coisa), aquilo que define e nomeia a Arquitetura de uma forma tal que se abre ao poço da essência, deixando bem claro que não são os edifícios que definem a Arquitetura, mas que ela "mora neles" (WRIGHT, 1958, p. 102, tradução nossa). Que maior abertura interpretativa se poderia esperar?

$\star \star \star$ 


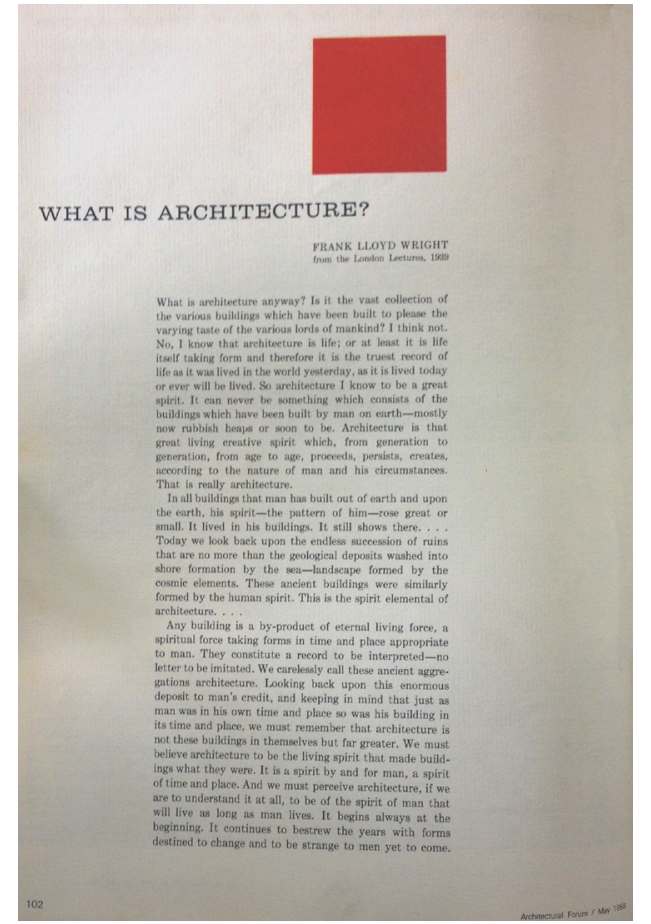

Figura 2. Página 102 da revista The Architectural Forum, New York, v. 108, n. 5, p.102, May 1958.

16. A convite do Royal Institute of British Architects (RIBA), Wright ministrou quatro palestras em Londres em maio de 1939. A transcrição dessas palestras foi publicada no mesmo ano pela editora Lund, Humphries, sob o título An Organic Architecture. Posteriormente, em 1953, essas palestras foram incluídas numa compilação de textos editada pela tora Horizon sob o título The Future of Architecture (WRIGHT, 1953). Os textos publicados em 1939 e em 1953 são exatamente iguais.

17. No texto de 1953, taste está no plural ("tastes").

18. No texto de 1953 , a frase está invertida: "No. I think not".

19. O texto de 1953 diz: "as it is being lived today".

20. O texto de 1953 diz: "No it is not something".

21. O texto de 1953 diz: "on his earth".

22. Essa parte final da frase não consta da versão de 1953.

\section{English Text}

\section{What is architecture?}

Frank Lloyd Wright

[excerpt] From de London Lectures, $1939^{16}$

[Publish at: The Architectural Forum, New York, v. 108 , n. 5, p.102, May 1958.]

[Com pequenas diferenças, o primeiro parágrafo a seguir, comparece no texto da palestra da "Quarta Noite" (Fourth Evening) nas conferências de Londres (WRIGHT, 1953, p. 288).]

What is architecture anyway? Is it the vast collection of the various buildings which have been built to please the varying taste ${ }^{17}$ of the various lords of mankind? I think not. No, ${ }^{18}$ I know that architecture is life; or at least it is life itself taking form and therefore it is the truest record of life as it was lived in the world yesterday, as it is lived today ${ }^{19}$ or ever will be lived. So architecture I know to be a great spirit. It can never be something ${ }^{20}$ which consists of the buildings which have been built by man on earth ${ }^{21}$ - mostly now rubbish heaps or soon to be. ${ }^{22}$ Architecture is that great living creative spirit which, from generation to generation, ${ }^{23}$ from age to age, proceeds, persists, creates, according to the nature of man and his circumstances. ${ }^{24}$ That is really architecture. ${ }^{25}$

[Os parágrafos a seguir não provém das conferências de Londres, mas de "Some aspects of the past and present of architecture", capítulo publicado na mesma edição de textos acima referidos (WRIGHT, 1953, p. 51-52).] $]^{26}$
In all buildings that man has built out of earth and upon the earth, his spirit - the pattern of him ${ }^{27}$ - rose great or small. It lived in his buildings. It still shows there $[. . .]^{28}$

Today we look back upon the endless succession of ruins that are no more than the geological deposits washed into shore formation by the sea ${ }^{29}$ - landscape formed by the cosmic elements. These ancient buildings were similarly formed by the human spirit. This is ${ }^{30}$ the spirit elemental of architecture [...]. ${ }^{31}$

Any building is a by-product of eternal living force, a spiritual force taking forms in time and place appropriate to man. They constitute a record to be interpreted $^{32}$-no latter to be imitated. ${ }^{33}$ We carelessly call these ancient aggregations architecture. ${ }^{34}$ Looking back upon this enormous deposit to man's credit, and keeping in mind that just as man was in his own time and place so was his building in its time and place, we must remember that architecture is not these buildings in themselves but far greater. We must believe architecture to be the living spirit that made buildings that they were. It is a spirit by and for man, a spirit of time and place. And we must perceive architecture, if we are to understand it at all, to be of the spirit of $\operatorname{man}^{35}$ that will live as long as man lives. It begins always at the beginning. It continues to bestrew the years with forms destined to change and to be strange to men yet to come. 
23. Na versão de 1953, essa express ão não está entre vírgulas.

24. Na versão de 1953, o final dessa frase é diferente: "according to the nature of man, and his circumstances as they both change."

25. Na versão de 1953, a frase está estruturada assim: "That really is architecture", uma forma mais impactante, uma vez que enfatiza isto. originalmente como um dos capítulos redigidos por Wright em Architecture and Modern Life, escrito por Baker Brownell e Frank Lloyd Wright (1937). entre vírgulas e não entre hifens. Embora pareça desimportante, essa mudança indica que alguém interferiu no texto, seja copiando-o mal, seja propositalmente. Alterações em hifens e vírgulas são geralmente propostas por um editor, não tanto pelo autor. Suspeitamos que quem montou esse texto não foi Wright (não que ele não fizesse isso; fazia e muito), porque esses pequenos detalhes sugerem que pode ter sido alguém da revista.

28. Suprimiu-se daí o trecho: "But common to all these workmanlike endeavors in buildings great or small, another spirit lived. Let us call this spirit, common to al
26. O texto foi publicado

27. No texto de 1953, está buildings, the great spirit, architecture". (Mas, comum todos esses esforços do trabalho humano em edifícios grandes ou pequenos, viveu outro espírito. Vamos chamar esse espírito, comum todos os edifícios, o grande espírito, de arquitetura.)29. Na versão de 1953, há uma vírgula em vez do hífen.

30. Na versão de 1953, está "It is", e não "This is".

31. O trecho suprimido diz: "The buildings are now dead to uses of present-day activity. They were sculptured by the spirit of architecture in passing, as inert shapes or the shore were sculptured by cosmic forces". (Os edifícios estão agora mortos para atividade de nossos dias. Foram esculpidos pelo espírito da arquitetura de passagem, como formas inertes da costa foram esculpidas por

32. Na versão de 1953, vírgula no lugar de hífen.

33. No texto de 1953, abre -se aí um novo parágrafo.

34. No texto de 1953 , a palavra architecture está entre aspas.

35. No texto de 1953, a frase é "to be a spirit of the spirit of man", o que evidentemente tem mais sentido.

36. "Os variados gostos", na versão de 1953 forças cósmicas.)

Tradução ao português

\section{O que é Arquitetura?}

Frank Lloyd Wright

Das palestras de Londres, 1939 [excerto]

O que é arquitetura, enfim? É um vasto conjunto dos muitos edifícios que foram construídos para agradar o variado gosto ${ }^{36}$ dos diversos senhores da humanidade? Penso que não. Não, ${ }^{37}$ sei que arquitetura é vida; ou, pelo menos, é a própria vida tomando forma e, portanto, é o registro mais verdadeiro da vida tal como foi vivida no mundo até ontem, como é vivida $^{38}$ hoje ou como sempre será vivida. Então sei que a arquitetura é um grande espírito. Nunca pode ser considerada como sendo os edifícios que foram construídos pelo homem na terra ${ }^{39}$ - na maioria agora um monte de lixo, ou que o serão em breve. A arquitetura é aquele grande espírito vivo criador que, de geração em geração, de tempo em tempo, prossegue, persiste e cria de acordo com a natureza do homem e com suas circunstâncias. Isso é realmente arquitetura.

Em todos os edifícios que o homem construiu de terra e sobre a terra, seu espírito - seu modelo - se elevou em maior ou menor grau. Habitava em seus edifícios. Ainda se mostra neles. [...] Hoje olhamos para trás, para a interminável sucessão de ruínas, que não são mais que depósitos geológicos banhados pelo mar para formar a costa - uma paisagem formada por elementos cósmicos. Esses edifícios usjt • arq.urb • número 24 | janeiro - abril de 2019 antigos foram criados de modo semelhante pelo espírito humano. Esse é o espírito fundamental da arquitetura. [...]

Todo edifício é um subproduto da eterna força vital, uma força espiritual que toma forma no tempo e no lugar adequados ao homem. Constituem um registro a ser interpretado - e não para ser imitado posteriormente. Descuidadamente, chamamos esses conjuntos antigos de arquitetura. Olhando para trás, para esse enorme depósito a crédito do homem, e tendo em mente que, assim como o homem estava em seu tempo e lugar, também os edifícios estavam colocados em seu tempo e em seu lugar, devemos lembrar que a arquitetura não é constituída por esses edifícios em si mesmos, mas é muito mais. Devemos acreditar que a arquitetura é o espírito vivo que fez dos edifícios o que foram. É um espírito pelo e para o homem, um espírito de tempo e lugar. $\mathrm{E}$ devemos perceber a arquitetura, se quisermos entendê-la, como sendo o espírito do homem que viverá enquanto o homem viver. Começa sempre pelo princípio. Continua a se espalhar pelos anos com formas destinadas a mudar e a serem estranhas aos homens que ainda estão por vir. ${ }^{40}$

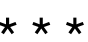


37. Se tomássemos a versão publicada em 1953, seria: "Não. Acho que não".

38. Na versão de 1953, seria "está sendo vivida hoje".

39. Na versão de 1953, seria: "em sua terra".

40. Agradecemos a revisão dessa tradução a Paulo $\mathrm{Y}$ Fujioka e a Julia V. Tourinho.

41. Muitos autores, por exemplo Hitchcock (1978), desconsideram essa publicação, porque não é um livro sobre arquitetura.

42. Transcrição da palestra de mesmo nome ministrada pelo arquiteto perante a Arts and Crafts Society na Hull House de Chicago.

43. Com as palestras "In the Realm of Ideas" e "To the Young Man on Architecture".

44. Foi publicado também in: Modern Architecture: Being the Kahn Lectures for 1930 Princeton: Princeton University Press, 1930, p. 7-23.

45. Em alguns casos, esse livro e um com o mesmo título, publicado em 1943, são considerados uma só obra (a de 1943), mas as muitas diferenças não são só temporais, e sim de organização, o que permite considerá-las duas obras separadas.

46. Alguns autores, como Hitchcock (1978), não consideram essa recompilação de textos um livro de autoria de Wright, pelo fato de haver sido editada por um terceiro.

47. Republicado até o falecimento do arquiteto com cinco livros, chegou até a sexta edição, de 1957. Ainda assim, existe um Book Six: Broadacre City, escrito em 1943, publicado privadamente por Wright.

48. Nova versão, revisada e ampliada, do livro The Disappearing City, de 1932.

49. Com a recompilação das palestras de Princeton (1930), Chicago (1931) e Londres (1939), além de outros escritos.

50. Alguns autores, como Zevi (1993), não consideram essa recompilação um livro de autoria de Wright, por haver sido editada por um terceiro. Mas, Hitchcock (1978, p. 32), por exemplo, a inclui.

51. Existe uma edição do mesmo ano, editada po Bramhall House (London), mas é considerada uma segunda edição.

52. Revisão e ampliação do livro When Democracy Builds, de 1945.
Livros de autoria de Frank Lloyd Wright (1 ${ }^{\mathrm{a}}$ edição) publicados durante a sua vida:

1. The Japanese Print: An Interpretation. ${ }^{41}$ Chicago: The Ralph Fletcher Seymour Co., 1912.

2. Art and Craft of the Machine. ${ }^{42}$ Chicago: National League of Industrial Art, 1902 [catálogo do Chicago Architectural Club]. 111 p.

3. Two lectures on architecture. ${ }^{43}$ Chicago: The Art Institute of Chicago, 1931.63 p. ${ }^{44}$

4. An Autobiography. ${ }^{45}$ New York: Longmans, Green \& Co., 1932. $371 \mathrm{p}$.

5. The Disappearing City. New York: William Farquhar Payson, $1932.90 \mathrm{p}$.

6. An Organic architecture: The Architecture of Democracy. London: Lund, Humphries, 1939. 56 p.

7. [Frank Lloyd Wright] On Architecture: Selected Writings, 1894-1940. ${ }^{46}$ New York: Duell, Sloan \& Pearce Inc., 1941. 275 p. [Frederick Gutheim, editor, escreve a introdução.]

8. An Autobiography. ${ }^{47}$ New York: Duell, Sloan \& Pearce Inc., 1943. 561 p. [Edição revisada e ampliada da publicação com o mesmo título de 1932.]

9. When Democracy Builds. ${ }^{48}$ Chicago: University of Chicago Press, 1945. 130 p.

10. Genius and the Mobocracy. New York: Duell, Sloan \& Pearce Inc., 1949. 113 p.

11. The Future of Architecture. ${ }^{49}$ New York: Horizon Press, 1953. $326 \mathrm{p}$.

12. The Nature House. New York: Horizon Press, 1954. 223 p.

13. An American Architecture ${ }^{50}$ New York: Horizon Press, $1955 .^{51} 267$ p. [Edgar Kaufmann, editor]
14. The Story of the Tower: the tree that escaped the crowded forest. New York: Horizon Press, 1956. $130 \mathrm{p}$.

15. A Testament. New York: Horizon Press, 1957. $256 \mathrm{p}$.

16. The Living City. ${ }^{52}$ New York: Horizon Press, 1958. 255 p.

Livros em coautoria entre o arquiteto Frank Lloyd Wright e outros autores ( $1^{\mathrm{a}}$ edição), publicados durante a vida do arquiteto:

1. The House Beautiful. Autores: William Channing Gannett e Frank Lloyd Wright (com introdução e notas de Paul Kruty). Chicago: Auvergne Press, $1897.80 \mathrm{p}$.

2. Architecture and Modern Life. Autores: Baker Brownell e Frank Lloyd Wright. New York: Harper \& Brothers, 1937. 339 p.

Livros com desenhos do arquiteto Frank Lloyd Wright (1 $1^{\text {a }}$ edição), publicados durante a vida do arquiteto:

1. Ausgeführte Bauten und Entwürfe von Frank Lloyd Wright. Berlin: Wasmuth, 1910.

2. Frank Lloyd Wright Ausgeführte Bauten. Berlin: Wasmuth, 1911.

3. Taliesin Drawings: Recent Architecture of Frank Lloyd Wright Selected from his Drawings. Wittenborn (Al): Schultz, 1952.

4. Drawings for a Living Architecture. New York: Horizon Press, 1959. 


\section{Referências:}

BACHELARD, Gaston. A poética do espaço. Trad. Antônio da Costa Leal e Lídia do Valle Santos Leal, 2013. Disponível em: <https://filosoficabiblioteca.files.wordpress.com/2013/11/bachelard-a-poc3a9tica-do-espaco.pdf>. Acesso em: $1 \mathrm{dez} .2018$

. La poética del espacio. Tradução espanhola de Ernestina de Champourcin. 2a ed. española da $8 a$ ed. francesa, $5 a$ reimp. México, DF: Fondo de Cultura Económica, 2000. 281 p.

A poética do espaço. Trad. Antonio de Pádua Danesi. São Paulo: Martins Fontes, 1989. $242 \mathrm{p}$.

La poétique de l'espace. 3ème ed. Paris: Les Presses Universitaires de France, 1961. $215 \mathrm{p}$.

BENEVOLO, Leonardo. História da arquitetura moderna. Trad. Ana M. Goldberger. São Paulo: Perspectiva, 1976. $813 \mathrm{p}$.

BLAKE, Peter. Master Builders: Le Corbuiser, Mies van der Rohe, Frank Lloyd Wright. Reedição da 2a ed. New York: Norton, 1996. 430 p.

Os grandes arquitetos. Frank Lloyd Wright. Trad. Pinheiro de Lemos. Rio de Janeiro: Record, 1966. v. 3. 141 p.
BROWNELL, Baker; WRIGHT, Frank Lloyd. Architecture and Modern Life. New York: Harper \& Brothers, 1937. $339 p$.

COHEN, Jean-Louis. 0 futuro da arquitetura desde 1889: uma história mundial. São Paulo: Cosac Naify, 2013. 528 p.

CURTIS, William J. R. La arquitectura moderna desde 1900. 3a ed. Trad. espanhola de Jorge Sainz. New York: Phaidon, 2006. 736 p.

DORFLES, Gillo. L'Architettura moderna. 6a ed. Milano: Aldo Garzanti, 1975. 166 p.

FRAMPTON, Kenneth. Wright's Writings: Reflections on Culture and Politics. New York: Columbia University Press, 2017. 143 p.

História crítica da arquitetura moderna. 1a ed. 3a tiragem. Tradução Jefferson Luiz Camargo. São Paulo: Martins Fontes, 2003. 470 p.

HITCHCOCK, Henry-Russell. Frank Lloyd Wright: obras 1887-1941. Trad. castelhana de Justo G. Beramendi. Barcelona: Gustavo Gili, 1978. $428 \mathrm{p}$. 
KRÜGER, Mário Júlio Teixeira. Introdução. In: ALBERTI, Leon Battista. Da arte edificatória. Lisboa: Fundação Calouste Gulbenkian, 2011, p. 17-130.

LAUGIER,Marc-Antoine. Essaisurl'Architecture. Paris: Duchesne, 1753. 310 p. Disponível em: <https://gallica.bnf.fr/ark:/12148/bpt6k856908/ f2.image $>$. Acesso em: 1 dez. 2018. Gallica.bnf. fr/Bibliothèque nationale de France (reprodução numerada de obras tombadas de domínio público provenientes das coleções da BnF).

LE CORBUSIER. Por uma arquitetura. 3a ed. Trad. Ubirajara Rebouças. São Paulo: Perspectiva, $1981.245 \mathrm{p}$.

. Vers une architecture. 2a ed. Paris: G. Crès, 1925. 206 p. Disponível em: <http://www. mondotheque.be/wiki/images/d/d4/Corbusier_ vers_une_architecture.pdf>. Acesso em: $1 \mathrm{dez}$. 2018. Gallica.bnf.fr/Bibliothèque nationale de France (reprodução numerada de obras tombadas de domínio público provenientes das coleções da BnF).

LE DICTIONNAIRE. Le Dictionnaire de définitions et synonymes. Disponível em: <http:// www.le-dictionnaire.com/>. Acesso em: $1 \mathrm{dez}$. 2018.

MARCUS VITRUVIUS POLLIO. De Architectura: Liber I. Disponível em: <http://penelope.uchi-
cago.edu/Thayer/L/Roman/Texts/Vitruvius/1* html>. Acesso em: 1 dez. 2018.

MIES VAN DER ROHE, Ludwig. Wir stehen in der Wende der Zeit: Baukunst als Ausdruck geistiger Entscheidung. Innendekoration, v. 39, n. 6, p. 262, jun. 1928.

[Aphorismus]. G - Material zur elementaren Gestaltung, Berlim, n. 1, p. 3, jul. 1923.

MYSTIC STAMP COMPANY. Disponível em: <https://www.mysticstamp.com/Products/ DisplayPicture.aspx?key=292765\&FileID=/pictures/ stamps_large/lg_302396.jpg>. Acesso em: 30 nov. 2019.

RAGON, Michel. Historia mundial de la arquitectura y del urbanismo modernos: ideologías e pioneros, 1800-1910. Trad. espanhola de Margarita Agullé. Barcelona: Destino, 1971. Tomo 1. $295 \mathrm{p}$.

VÁZQUEZ RAMOS, Fernando Guillermo. Mies van der Rohe na viragem de uma época. Revista Interfaces, Rio de Janeiro: UFRJ, v. 2, n. 25, p. 53-64, jul./dez. 2016. Disponível em: <http:// www.cla.ufrj.br/images/revista25/05_IF25_mies-van-der-rohe.pdf>. Acesso em: 30 nov. 2018.

- Mies van der Rohe define Arquitetura: aforismo, 1923. Uma tradução e reflexões sobre os significados do preceito. Arq.urb, São Paulo, 
n. 10, p. 168-178, 2013. Disponível em: <https:// www.usjt.br/arq.urb/numero-10/13-classicos-fernando-g-vazquez.pdf>. Acesso em: 30 nov. 2018.

. O desenho e a arquitetura em Leon Battista Alberti e Giorgio Vasari. In: ENCONTRO DE HISTÓRIA DA ARTE, 7., 2011, Campinas. Anais: Os caminhos da história da arte desde Giorgio Vasari: consolidação e desenvolvimento da disciplina. Campinas: Centro de História da Arte e Arqueologia/Instituto de Filosofia e Ciências Humanas, Universidade Estadual de Campinas, Campinas, 2011. Disponível em: <https://www. ifch.unicamp.br/eha/atas/2011/Fernando\%20 Guillermo.pdf>. Acesso em: 30 nov. 2018.

VITRÚVIO. Tratado de arquitetura. Trad. Justino Maciel. São Paulo: Martins Fontes, 2007. 556 p.
WRIGHT, Frank Lloyd. What is architecture? The Architectural Forum: the magazine of building, New York, v. 108, n. 5, p. 102, maio 1958. Disponível em: <http://www.usmodernist.org/AF/AF1958-05.pdf>. Acesso em: 1 dez. 2018.

The Future of Architecture. New York: Horizon Press, 1953. 326 p.

Frank Lloyd Wright On Architecture: Selected Writings 1894-1940. New York: Duell, Sloan \& Pearce Inc., 1941. 275 p. [Frederick Gutheim, editor]

ZEVI, Bruno. Frank Lloyd Wright. 5a ed. Trad. Fernando Pereira Cavadas. Barcelona: Gustavo Gili, 1993. 300 p. 